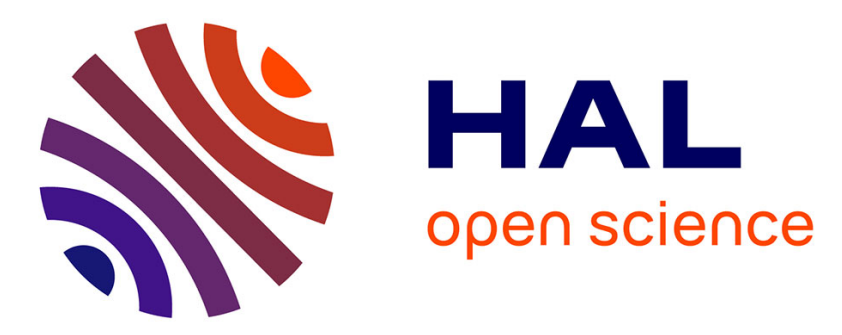

\title{
Kinetic study of furan and furfural generation during baking of cake models
}

Rohit Srivastava, Josselin Bousquières, Mayela Cepeda Vasquez, Stéphanie Roux, Catherine Bonazzi, Barbara Rega

\section{- To cite this version:}

Rohit Srivastava, Josselin Bousquières, Mayela Cepeda Vasquez, Stéphanie Roux, Catherine Bonazzi, et al.. Kinetic study of furan and furfural generation during baking of cake models. Food Chemistry, 2018, 267, pp.329-336. 10.1016/j.foodchem.2017.06.126 . hal-01746020

\section{HAL Id: hal-01746020 \\ https://hal.science/hal-01746020}

Submitted on 28 Mar 2018

HAL is a multi-disciplinary open access archive for the deposit and dissemination of scientific research documents, whether they are published or not. The documents may come from teaching and research institutions in France or abroad, or from public or private research centers.
L'archive ouverte pluridisciplinaire HAL, est destinée au dépôt et à la diffusion de documents scientifiques de niveau recherche, publiés ou non, émanant des établissements d'enseignement et de recherche français ou étrangers, des laboratoires publics ou privés. 


\title{
Kinetic study of furan and furfural generation during baking of cake models
}

\author{
R. Srivastava, J. Bousquières, M. Cepeda-Vázquez, S. Roux, C. Bonazzi, B. Rega* \\ UMR Ingénierie Procédés Aliments, AgroParisTech, Inra, Université Paris-Saclay, 91300 Massy, France
}

\section{A R T I C L E I N F O}

\section{Article history:}

Received 24 February 2017

Received in revised form 25 May 2017

Accepted 20 June 2017

Available online $\mathrm{xxxx}$

\section{Keywords:}

Caramelization

Maillard reaction

Quantification

Glucose

Leucine

Stable isotope dilution assay

Thermal processing

HS trap

\begin{abstract}
A B S T R A C T
This study describes the kinetics of furan and furfural generation in a cake model, for the first time. These process-induced compounds impact safety and sensory aspects of baked products. Understanding their generation with regards to process dynamics will serve food quality design. However, the complexity of real products makes this task challenging. This work provides a novel approach to understand and model chemical reactivity by implementing an inert cake model (starch, water and cellulose), specifically designed for mimicking a sponge cake structure. The addition of reaction precursors (glucose and leucine) to follow Maillard and caramelization reactions, resulted in browning and generated considerable levels of furanic compounds (up to $17.61 \mathrm{ng} / \mathrm{g}$ for furan and $38.99 \mu \mathrm{g} / \mathrm{g}$ for furfural, dry basis). Multiresponse data modeling resulted in a kinetic model which adequately describes experimental concentrations and makes it possible to estimate the degradation of precursors and the behavior of two hypothetic intermediates.
\end{abstract}

() 2017 Elsevier Ltd. All rights reserved.

\section{Introduction}

Thermal processing of food is a dynamic process involving heat and mass transfer, thus leading to a number of physical and chemical changes. Baking is particularly interesting as high temperatures trigger reactions leading to the generation of numerous compounds. Many of them contribute to quality attributes such as color and flavor. Indeed, it has been shown that more than 540 volatile compounds can be formed during baking of cereal products (Cho \& Peterson, 2010). Moreover, the generation of quality-related volatile compounds has been extensively studied in different bakery goods and the effect of processing conditions has also been investigated for some of them (Ait Ameur, Mathieu, Lalanne, Trystram, \& Birlouez-Aragon, 2007; Fehaili, Courel, Rega, \& Giampaoli, 2010; Petisca, Henriques, PérezPalacios, Pinho, \& Ferreira, 2014; Pico, Bernal, \& Gómez, 2015; Zoller, Sager, \& Reinhard, 2007). Thermal reactivity, however, can lead not only to expected sensory characteristics, but also to the development of safety-related compounds. As a consequence, their mitigation is rapidly becoming a new challenge for food formulation and process engineering, since it has to be carried out without affecting the flavor profile of such products (Rannou, Laroque, Renault, Prost, \& Sérot, 2016).

\footnotetext{
* Corresponding author.

E-mail address: barbara.rega@agroparistech.fr (B. Rega).
}

Among process-induced compounds, furanic compounds are of paramount interest. Furan has been classified as "possibly carcinogenic to humans" (Group 2B) by the International Agency for Research on Cancer (International Agency for Research Center on Cancer, 1995) and in recent years many studies found nonnegligible furan levels in starchy and baked goods in a wide concentration range depending on the product (up to $200 \mathrm{ng} / \mathrm{g}$ ) (Wegener \& López-Sánchez, 2010; Zoller et al., 2007). This is mainly due to different formulation and processing conditions. On the other hand, furfural is known to be an odor-impacting compound in cereal products (Pico et al., 2015; Rega, Guerard, Delarue, Maire, \& Giampaoli, 2009). In bakery products like cakes, breads and biscuits, furfural concentration also varies across a wide range of concentrations; however, it is usually found at higher levels than furan (Cepeda-Vázquez, Blumenthal, Camel, \& Rega, 2017; Huault, Descharles, Rega, Bistac, \& Giampaoli, 2016; Petisca et al., 2014).

The formation of these two compounds is closely linked as it can be due to mechanisms such as caramelization and Maillard reactions, occurring simultaneously during baking. Nevertheless, thermal degradation of certain amino acids (serine, alanine, aspartic acid, threonine, cysteine) and thermal oxidation of ascorbic acid and of polyunsaturated fatty acids can contribute to furan generation as well (Crews \& Castle, 2007). Furfural is generated mainly by 1,2-enolisation pathway via 3-deoxyosone (Kroh, 1994; Nguyen, Fels-Klerx, Peters, \& van Boekel, 2016; Rannou et al., 2016). On the other hand, Perez Locas and Yaylayan (2004) showed that furan 
is predominantly formed through the 2,3-enolisation pathway in a glucose and serine model. The degradation of hexoses, through direct enolization in the case of caramelization or enolization of Amadori compounds in the Maillard reaction, is the initial step. Reactivity studies may thus provide useful insight on such reaction pathways, in order to find meaningful optimization strategies towards furanic compounds occurrence.

Sponge cake is a good model to study the generation of these compounds as it contains all the precursors (sugars, proteins, amino acids, lipids) needed to trigger different pathways. It also has an alveolar structure that promotes uniform heat distribution throughout the product (Rega et al., 2009; Zhang et al., 2012). However, the complexity of the ingredients composition always makes it difficult to indicate the exact mechanism behind the generation and degradation of compounds in real products, due to the wide range of possible precursors and intermediates. This explains why the generation of reaction markers has been widely investigated in simpler liquid, semi-liquid and food models and mainly with respect to process and formula parameters (Ait Ameur et al., 2007; Blank, Devaud, Matthey-Doret, \& Robert, 2003; Nie et al., 2013; Owczarek-Fendor et al., 2012; Mariotti-Celis, Zúñiga, Cortés, \& Pedreschi, 2017). Nevertheless, findings in such simplified models cannot be directly extrapolated to understand the kinetics occurring in solid food, as they neglect the effect of the complex composition and structure of the food matrix. In fact, coupling reaction kinetics to reproducible thermal conditions is key to mapping the evolution of individual reactions during baking in a precise manner (Fehaili et al., 2010; Vleeschouwer, Plancken, Loey, \& Hendrickx, 2009).

Hence, in order to fully comprehend the reaction schemes and their kinetics in solid food, there is a need for food models which can provide similar structures, in terms of reaction surfaces and transfers, as those of a real food. Bousquières, Bonazzi, and Michon (2017) recently developed a cake model having similar structural properties to those of a sponge cake but formulated with non-reactive ingredients.

To date, there are no studies focusing on the kinetics and modeling of furan generation during the processing of a solid food, due to the analytical challenges that furan analysis represents. Only recently Palmers et al. (2015) proposed a kinetic modeling of furan formation during storage of shelf-stable fruit juices, based on an empirical, logistic model. More recently, Kocadaglı and Gökmen (2016) described the formation and degradation of reaction markers in low moisture glucose/wheat flour systems by applying a multiresponse kinetic model for isomerization and degradation reactions of glucose. This approach seems promising to be further applied to furan generation studies in more structured food products.

The aim of this work is to perform a kinetic study of furan and furfural generation by means of a cake model containing glucose and leucine as precursors of caramelization and Maillard reactions. In this regard, the model's inertness towards producing any of the two compounds by itself was preliminarily assessed. An optimized analytical method for the simultaneous quantification of furan and furfural over a wide range of concentrations (Cepeda-Vázquez et al., 2017) was applied, in order to follow these furanic markers through the baking process under suitable conditions for kinetic modeling applications.

\section{Material and methods}

\subsection{Reagents and ingredients}

Furan-d4 $(\geq 98 \%)$ and l-leucine $(\geq 99 \%)$ were purchased from Sigma-Aldrich (St. Louis, MO). Furfural-d4 ( $\geq 99.7 \%$ ) was obtained from CDN Isotopes (Pointe-Claire, Canada) and methanol ( $\geq 99.9 \%$ ) was bought from Carlo Erba (Val de Reuil, France). Food grade hydroxypropylmethylcellulose (HPMC) and methylcellulose (MC) were purchased from Dow Chemical Company (Midland, $\mathrm{MI}$ ), corn starch from Cargill (Wayzata, MN) and d-glucose monohydrate was kindly provided by Roquette Frères (France).

\subsection{Cake model batter preparation}

Reference cake models were produced according to an optimized method by Bousquières et al. (2017), using corn starch and a hydrocolloid mixture to obtain targeted rheological properties of the batter and thus reproduce the alveolar structure of a baked cake. HPMC and MC were mixed in adequate proportions $(0.35 \%$ and $0.47 \%$, respectively, see Table 1$)$ and dispersed in hot distilled deionized water at $80^{\circ} \mathrm{C}$. The dispersion was refrigerated at $4{ }^{\circ} \mathrm{C}$ for $20 \mathrm{~h}$ for solvation and then battered for $10 \mathrm{~min}$ with a mixer (KitchenAid 5KSM150, Benton Harbor, MI) equipped with a vertical whisk at nominal speed 10 . Starch was gradually added to the foam at speed 2 over $40 \mathrm{~s}$, and the mixture was further blended for $2 \mathrm{~min} 20 \mathrm{~s}$ at the same speed. Two additional cake models were designed to study caramelization and Maillard reaction: model $\mathrm{G}$ containing glucose only, and model $\mathrm{G}+\mathrm{L}$ containing both glucose and leucine (Table 1 ). In G and $G+$ L formulas, glucose was added from the beginning to the HPMC and MC mixture and leucine was added with starch, for solubility and functional reasons. The amount of glucose was selected according to sugar content in a reference sponge cake, whereas leucine was chosen based on the content in free amino acids and total free amino groups measured in the same reference product (Bousquières et al., 2017; Fehaili et al., 2010) and considering that free amino acids are more reactive than proteins (Kearsley \& Dziedzic, 1995).

\subsection{Baking protocol}

\subsubsection{Baking conditions}

For each cake model, seven aluminum molds (dimensions: $8 \mathrm{~cm} \times 4.5 \mathrm{~cm} \times 3.5 \mathrm{~cm}$ ) were filled with $60 \mathrm{~g}$ of batter and baked at $170^{\circ} \mathrm{C}$ at high ventilation speed (nominal conditions) in an oven specifically designed for uniform and reproducible baking and kinetic measurements (Fehaili et al., 2010). Whole cake models were sampled at different baking time intervals $(4,10,25,34,60$ and $90 \mathrm{~min}$ ), stored immediately in air tight containers and kept at $20^{\circ} \mathrm{C}$. In order to evaluate the inertness of the reference cake model (R), one additional baking condition at $200^{\circ} \mathrm{C} / 34 \mathrm{~min}$ was tested.

\subsubsection{Temperature and humidity measurements}

For the nominal baking conditions, temperatures were measured at the bottom and at different points inside the model cake $(4,8$, and $12 \mathrm{~mm}$ in height from the bottom) by means of an mold of similar dimensions, equipped with four thermocouples stretched and aligned in the center. Moreover, the temperature at the surface was measured by means of an Optris CT LT infrared

Table 1

Ingredient proportions in different model cakes.

\begin{tabular}{llll}
\hline Ingredients & Model R $(\mathrm{g})$ & Model G $(\mathrm{g})$ & Model G + L $(\mathrm{g})$ \\
\hline HPMC & 0.35 & 0.47 & 0.47 \\
MC & 0.46 & 0.62 & 0.62 \\
Leucine & - & - & 5.00 \\
Glucose & - & 20.00 & 20.00 \\
Corn starch & 36.55 & 36.45 & 36.45 \\
Water & 62.64 & 62.46 & 62.46 \\
Total Mix & 100 & 120 & 125 \\
\hline
\end{tabular}


pyrometer (Optris GmbH, Berlin, Germany) positioned $10 \mathrm{~cm}$ above the product according to Fehaili et al. (2010). Air humidity in the oven was measured using a Hygrox-C2 probe (McQueen Cairns Technology-Brentford, UK), following Fehaili et al. (2010). Temperatures were automatically recorded every $10 \mathrm{~s}$ and air humidity every second by a data logger driven by LabVIEW software (National Instruments-Austin, TX). Three independent baking experiments were performed for each model.

Product moisture content was determined by weighing cake samples before and after complete desiccation after $24 \mathrm{~h}$ in a ventilated oven (Raypa) set at $105 \pm 2{ }^{\circ} \mathrm{C}$. The weighing was performed using a balance (Mettler Toledo, AB204) with an accuracy of $0.0001 \mathrm{~g}$.

\subsection{Furan and furfural analysis}

Furan and furfural quantitative analysis was performed on cake models for each baking interval and for each formula, following a protocol previously optimized for the headspace trap extraction (HS trap) of these furanic compounds from sponge cake (CepedaVázquez et al., 2017). Sampling procedure (blending) and concentration of standard isotopes were adapted for the specificities of the cake models.

\subsubsection{Material preparation}

Furan and furfural analysis at trace level can be affected by external pollution. To prevent this, glassware was kept in an oven at $50{ }^{\circ} \mathrm{C}$ for $24 \mathrm{~h}$ prior to use and headspace vials were heated at $350{ }^{\circ} \mathrm{C}$ for at least $1 \mathrm{~h}$, and then stored in plastic bags.

\subsubsection{Stock and working solution preparation}

Stock solutions of furan-d4 and furfural-d4 were prepared in methanol $(2.5 \mathrm{mg} / \mathrm{mL})$ and stored in amber glass bottles at $20^{\circ} \mathrm{C}$ for a maximum of 30 days. A working solution was prepared daily by serial dilution in ultrapure water (Millipore; $>5 \mathrm{M} \Omega \cdot \mathrm{cm}$ at $25^{\circ} \mathrm{C}$ ) with furan-d4 and furfural-d4 concentrations set as $0.25 \mu \mathrm{g} / \mathrm{mL}$ and $25 \mu \mathrm{g} / \mathrm{mL}$ respectively. Room temperature was kept below $20{ }^{\circ} \mathrm{C}$ to prevent furan and furfural loss through diffusion. The solutions and samples were prepared in separate and well ventilated rooms to avoid contamination during sample preparation.

\subsubsection{Vial preparation}

The frozen cake models were blended in ice-cold water using a Grindomix GM 200 Grinder (Retsch, Haan, Germany) at $4000 \mathrm{rpm}$ for $10 \mathrm{~s}$. The water-to-sample ratio (dry basis) was set to 16 following Cepeda-Vázquez et al. (2017). Ten grams of the resulting mix were poured into a $20-\mathrm{mL}$ headspace vial followed by addition of $40 \mu \mathrm{L}$ of internal standard mix solution. This protocol was repeated four times to prepare four replicates. The vials were sealed with an aluminum cap bearing a polytetrafluoroethylene-silicone septum and vortexed for $10 \mathrm{~s}$ before analysis.

\subsubsection{HS trap-GC/MS analysis}

Furan and furfural were analyzed using a TurboMatrix Headspace Sampler HS 40 Trap (Perkin Elmer, Waltham, MA) coupled with a TRACE ${ }^{\mathrm{TM}}$ Ultra Gas Chromatograph and $\mathrm{ISQ}^{\mathrm{TM}}$-mass spectrometer (Thermo Scientific, Rodano, Italy). During extraction, needle and transfer line temperatures were maintained at $75^{\circ} \mathrm{C}$ and $100{ }^{\circ} \mathrm{C}$, respectively. Vials were pressurized to 40 psi for $0.5 \mathrm{~min}$, followed by a decay time of $2 \mathrm{~min}$. Volatile compounds were concentrated in an air monitoring trap (Carbotrap and Carbosieve SIII, Perkin Elmer) during 4 pressurization cycles. A dry purge of the trap was then performed for $0.9 \mathrm{~min}$ to prevent moisture entering the GC column. Trap temperature was increased from 28 to $250{ }^{\circ} \mathrm{C}$ (at $40^{\circ} \mathrm{C} / \mathrm{s}$ ) and compounds desorbed into the GC for $0.2 \mathrm{~min}$ using split mode $(1: 8)$ with injector temperature set to $250^{\circ} \mathrm{C}$.
Volatile analytes were separated by a VF-WAXms column (60 m length $\times 0.25 \mathrm{~mm}$ internal diameter, $0.5 \mu \mathrm{m}$ film thickness; Agilent Technologies, Santa Clara, CA) using helium as a carrier gas with a constant flow rate of $1.2 \mathrm{~mL} / \mathrm{min}$. Oven temperature was maintained at $40^{\circ} \mathrm{C}$ for $4 \mathrm{~min}$, then increased by $10^{\circ} \mathrm{C} / \mathrm{min}$ until $150{ }^{\circ} \mathrm{C}$, followed by $20^{\circ} \mathrm{C} / \mathrm{min}$ until $240^{\circ} \mathrm{C}$, which was held for $8 \mathrm{~min}$. Mass spectrometric detection (EI mode at $70 \mathrm{eV}, 0.2 \mathrm{~s} / \mathrm{scan}$ ) was carried out in both full scan and selected ion monitoring (SIM) mode for furan ( $\mathrm{m} / \mathrm{z}: 39$ and 68$)$, furan-d $4(\mathrm{~m} / \mathrm{z}: 42$ and 72), furfural $(\mathrm{m} / \mathrm{z}$ : 39, 95 and 96) and furfural-d4 ( $\mathrm{m} / \mathrm{z}: 42,98$ and 100). Ions depicted in "italics" were used for quantification. The method performances measured were: repeatability (RSD: $\leq 3.3 \%$ for furan and $\leq 2.6 \%$ for furfural), intermediate precision (RSD: $4.0 \%$ for furan and $4.3 \%$ for furfural), linearity range $\left(0.99-300 \mathrm{ng} \mathrm{g}^{-1}\right.$ and for furan and $41.1-9000 \mathrm{ng} \mathrm{g}^{-1}$ for furfural), limit of detection (LOD, 0.50 $\mathrm{ng}_{\text {furan }} \mathrm{g}_{\text {sample dry basis }}^{-1}$ and $10.2 \mathrm{ng}_{\text {fufural }} \mathrm{g}_{\text {sample dry basis }}^{-1}$ ), limit of quantification (LOQ, $0.99 \mathrm{ng}_{\text {furan }} \mathrm{g}_{\text {sample dry basis }}^{-1}$ and $41.1 \mathrm{ng}_{\text {fufural }}$

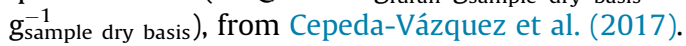

\section{Results and discussions}

\subsection{Analysis of baking conditions}

\subsubsection{Loss in moisture content during baking}

As expected, moisture content (MC) of cake models progressively decreased during the course of baking, similar to any baked product. Initial MC for the batter was clearly lower for models $G$ and $\mathrm{G}+\mathrm{L}$ (1.2 and $1.1 \mathrm{~g} / \mathrm{g}$ dry basis, respectively) than for model $\mathrm{R}(2.0 \mathrm{~g} / \mathrm{g}$ dry basis), due to the presence of glucose. However, the drying curves were similar for all formulas, with normalized moisture contents $\left(\mathrm{MC} / \mathrm{MC}_{0}\right)$ varying from 1 (batter) to 0.25 (Fig. 1A). This result shows that the presence of precursors did not modify the drying behavior of cake models. Humidity measurements inside the oven (RSD: 7\%) also showed a similar trend for models $G$ and $G+L$ (Fig. 1B). Heat supply led to a sudden evaporation of moisture from cake models, causing a steep increase in humidity inside the oven during the initial few minutes, and later decreased gradually with time. The loss of moisture from the surface of the product forms a dry zone or crust which gradually expands towards the center of the model as baking proceeds, as reported by Purlis (2010).

\subsubsection{Temperature profiles of models with precursors}

The models with precursors, G and G + L, displayed similar temperature profiles including confidence intervals. Hence, only the results for model $\mathrm{G}+\mathrm{L}$ are presented in Fig. $1 \mathrm{C}$. In order to consider the differences in initial temperatures of the batter between repetitions, data were first non-dimensionalized $\left(T^{*}=\left(T-T_{\infty}\right)\right.$ / $\left(T_{0}-T_{\infty}\right)$, where $T$ is the batter temperature, $T_{\infty}$ the temperature in the oven and $T_{0}$ the initial temperature of the batter) and then recalculated using a common initial value (i.e. $20^{\circ} \mathrm{C}$ ). Results show that the repeatability of temperature measurements in different locations during baking was good, with a low standard deviation (RSD $\approx 1.5 \%$ ), except for the surface temperature (RSD $\approx 3 \%$ ). The higher variability was attributed to accuracy of the optical pyrometer. Temperatures at the surface and at the bottom of the cake models increased rapidly. The surface, which was exposed to convective hot air, dried up quickly, reaching $100{ }^{\circ} \mathrm{C}$ in less than 2 min of baking, while at the bottom, where conduction was the prominent mode of heat transfer, it took more than $10 \mathrm{~min}$ to reach the same temperature. As expected, internal layers showed slower increase in temperature and remained at a temperature much lower than the surface in direct contact with heat (e.g., $111^{\circ} \mathrm{C}$ at $8 \mathrm{~mm}$ from the bottom). It should be noted that at $12 \mathrm{~mm}$ above the bottom, temperature remained close to $100^{\circ} \mathrm{C}$ until the end 

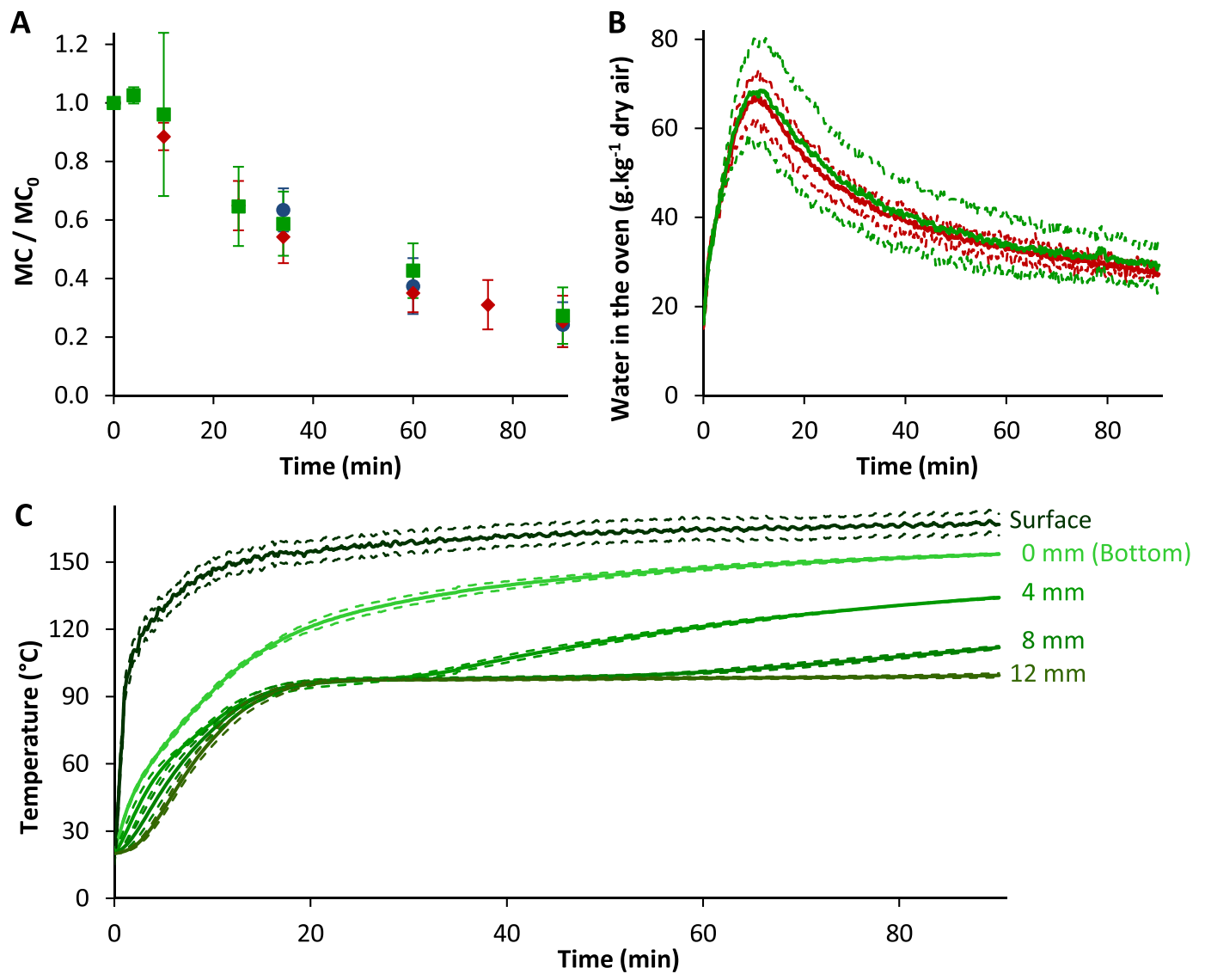

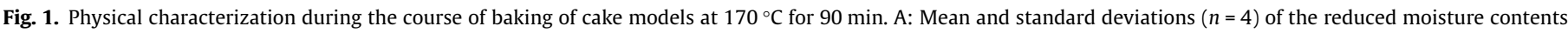

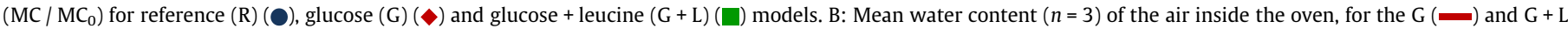

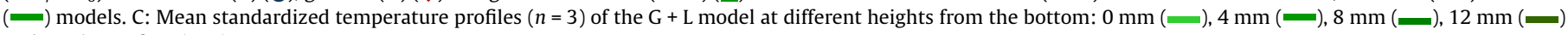
and on the surface ( $(\mathbf{m})$.

of baking. Therefore, it can be assumed that from this level to the core, temperature also remained close to $100^{\circ} \mathrm{C}$ due to the water evaporation phenomenon as in a standard product crumb. From these data we can infer that after 90 min of baking at $170{ }^{\circ} \mathrm{C}$, a crust of about $8 \mathrm{~mm}$ is formed at the bottom of the cake models and it is considered as a minimum for all the sides where heat transfer is higher due to convection.

\subsection{Analysis of reactivity in different model cakes}

The choice of precursors is undoubtedly very important in any reactivity study. Glucose and leucine have been used in a number of studies pertaining to volatiles generation (Lutz, Aserin, \& Garti, 2005; Pacyński, Wojtasiak, \& Mildner-Szkudlarz, 2015; Samsudin, Rongtao, \& Said, 1996). Glucose, being one of the most reactive reducing sugars, provides faster and simple reactions. Leucine on the other hand, was chosen on the fact that it cannot contribute to furan generation by itself, hence confining the scope of reaction pathways to Maillard and caramelization reactions only (Perez Locas \& Yaylayan, 2004; Vranová \& Ciesarová, 2009). Also, leucine is a known precursor of 3-methylbutanal, an odor active compound in sponge cake (Whitfield, 1992).

\subsubsection{Browning development}

Browning was dramatically different for the different models $R$, $G$ and $G+L$, even though thermal phenomena at the surface and dehydration process were the same (Fig. 2). Indeed, model R, in the absence of precursors, showed no apparent browning even after 90 min of baking, unlike the models $G$ and $G+L$ which devel- oped light and dark browning, respectively. It could then be inferred that browning of cake models, and thus reactivity, were only due to the addition of chemical precursors (glucose and leucine) and not to other physical parameters such as heat supply or water content. In model G, where only glucose is present, browning can only be induced by the products of glucose degradation through the caramelization pathway (Kroh, 1994). In model G $+\mathrm{L}$, Maillard reactions are promoted due to the presence of a free amino source (leucine) along with glucose. Under these conditions, color formation is assumed to be due to melanoidins and furfural derivatives (Purlis, 2010). The darker color of the $\mathrm{G}+\mathrm{L}$ model actually shows the effectiveness of leucine towards the formation of such pigments through the Maillard pathway and Strecker degradation.

Fig. 2 also shows that browning after 90 min of baking was specifically located at the most external layer of $G$ and $G+L$ products, where local temperatures reached $159^{\circ} \mathrm{C}$ (Fig. 1C). In fact color formation in bakery products requires temperatures $\geq 120^{\circ} \mathrm{C}$ and water activity $\leq 0.6$ as reported by Purlis and Salvadori (2009). However, in this context color is only used as easy and overall indicator of reactivity and preliminary to further chemical determination of specific reaction markers.

\subsubsection{Inertness of the reference model toward furanic compounds generation}

Model $\mathrm{R}$ is composed mostly of starch, water and small amounts of cellulose derivatives. These components were selected because of their functionality, and also for their known stability at high temperatures (Aggarwal \& Dollimore, 1998; Bousquières 


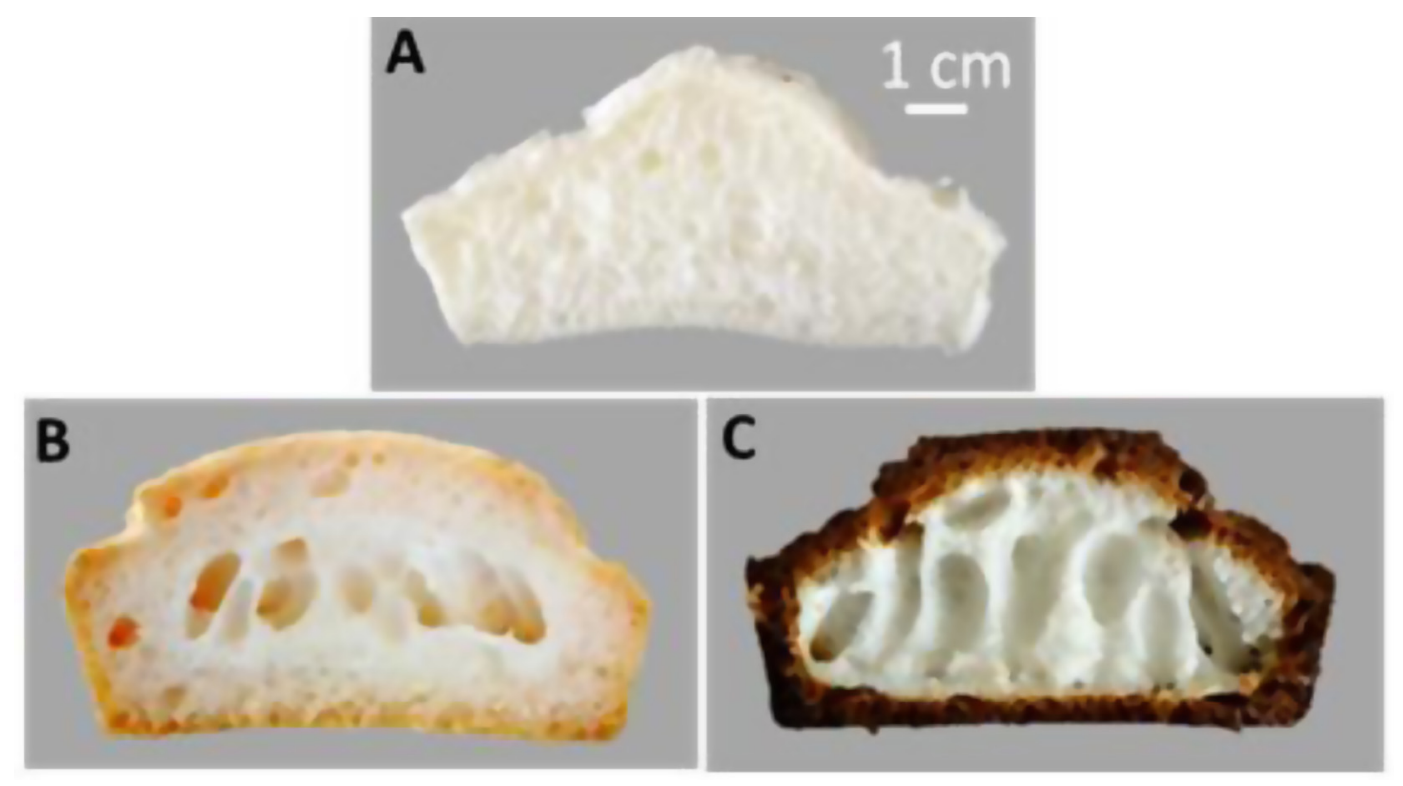

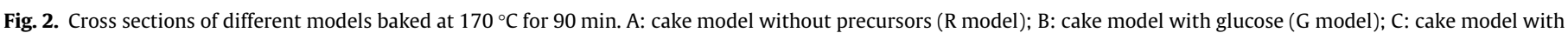
glucose and leucine $(\mathrm{G}+\mathrm{L}$ model $)$.

et al., 2017; Liu, Xie, Yu, Chen, \& Li, 2009). The inertness of model R (without precursors) was tested over a wide baking range $\left(170{ }^{\circ} \mathrm{C} / 34 \mathrm{~min}\right.$ to $200^{\circ} \mathrm{C} / 34 \mathrm{~min}$ ), in order to assess its suitability to study the generation of furanic compounds during baking. No trace of furfural was quantified at any of the tested conditions. Only furan was found in ppb traces, around the LOQ when the highest heat loads were applied: at $170{ }^{\circ} \mathrm{C}$ when baking time was extended to $90 \mathrm{~min}$ or when the temperature was raised from 170 to $200{ }^{\circ} \mathrm{C}$ for $34 \mathrm{~min}$ (see Supplementary Material). Such furan traces could be due to lipid residues present in corn starch. These levels can be considered as the base limit for analyses run under these conditions $\left(170^{\circ} \mathrm{C} / 90 \mathrm{~min}\right.$ and $\left.200^{\circ} \mathrm{C} / 34 \mathrm{~min}\right)$. Overall, the model $\mathrm{R}$ can be considered inert and appropriate to study chemical reactivity according to analytical performances and within applied thermal treatments.

\subsubsection{Furan and furfural generation in cake models containing precursors}

Cake models were found to produce furan and furfural in nonnegligible amounts when added with glucose ( $G$ model) and glucose along with leucine ( $\mathrm{G}+\mathrm{L}$ model). Furanic compounds levels were however very different as shown in Table 2: furfural was quantified in the ppm range while furan was only detected in trace amounts (ppb range) at the end of baking. For both compounds, concentrations increased with baking time, but were differently influenced by the nature of precursors. Indeed, furfural was formed

Table 2

Furan and furfural contents in models containing glucose (model G) and glucose plus leucine (model $\mathrm{G}+\mathrm{L}), n=4$.

\begin{tabular}{lllll}
\hline $\begin{array}{l}\text { Compound level } \\
(\mathrm{ng} / \mathrm{g} \text { dry basis })\end{array}$ & & \multicolumn{3}{c}{ Baking duration at $170{ }^{\circ} \mathrm{C}$} \\
\cline { 2 - 5 } & & $10 \mathrm{~min}$ & $34 \mathrm{~min}$ & $90 \mathrm{~min}$ \\
\hline \multirow{3}{*}{ Furan } & Model & & & \\
& $\mathrm{G}$ & $<\mathrm{LOQ}$ & $<\mathrm{LOQ}$ & $12.14 \pm 0.82$ \\
& $\mathrm{G}+\mathrm{L}$ & $<\mathrm{LOQ}$ & $1.55 \pm 0.04$ & $17.61 \pm 1.47$ \\
Furfural & Model & & & \\
& $\mathrm{G}$ & $<\mathrm{LOQ}$ & $583 \pm 17$ & $6293 \pm 193$ \\
& $\mathrm{G}+\mathrm{L}$ & $790 \pm 23$ & $8677 \pm 126$ & $38986 \pm 939$ \\
\hline
\end{tabular}

at much higher concentrations in the $G+L$ model than in the $G$ model. We can therefore infer that the difference in the concentration of furanic compounds in the cake models is only due to reactants, since baking conditions were strictly identical between $G$ and $\mathrm{G}+\mathrm{L}$ models. Interestingly, despite the browning level in $\mathrm{G}$ and $G+L$ models suggesting a different progress of reactions, furan concentrations remained in the same range for both models, while furfural concentrations significantly increased in model $\mathrm{G}+\mathrm{L}$.

In model $\mathrm{G}$, furfural was only detected after 34 min of baking. This corresponds to very high temperatures at the surface of the product $\left(139 \pm 2{ }^{\circ} \mathrm{C}\right.$ and $159 \pm 5{ }^{\circ} \mathrm{C}$ at the bottom and top of the product, respectively, Fig. 1C), which can trigger caramelization, the only thermal reaction assumed to occur in this model. These results are thus coherent with previous studies in model systems showing that caramelization reaction requires temperatures over $120^{\circ} \mathrm{C}$ for glucose degradation (Hurtta, Pitkänen, \& Knuutinen, 2004; Kroh, 1994). On the other hand, in model G + L, the presence of leucine seems to promote earlier furanic compound generation through Maillard reaction, such as furfural, which is detected at $10 \mathrm{~min}$ of baking. Such baking time corresponds to lower surface temperatures $\left(100 \pm 5{ }^{\circ} \mathrm{C}\right.$ and $146 \pm 5^{\circ} \mathrm{C}$ at the bottom and top of the product, respectively, Fig. 1C). These results show that under caramelization conditions, glucose is not very prone to form furan, leading however to non-negligible amounts of furfural. When adding leucine, the Maillard reaction is activated at temperatures lower than those measured for caramelization in the $G$ model $\left(139^{\circ} \mathrm{C}\right)$, leading to very high concentrations of furfural, while furan concentration remains low at the end of baking.

\subsection{Kinetic modeling of furan and furfural generation in cake models}

A simplified reaction scheme leading to the formation of furan and furfural from glucose and leucine in the model cakes is presented (Fig. 3A). Glucose can undergo thermal degradation via caramelization (C), leading to $\alpha$-dicarbonyl intermediates like 1 and 3-deoxyosones. These same intermediates can, however, be also obtained by enolisation and deamination of the Amadori product formed through Maillard reaction when glucose reacts with leucine (MR) under baking conditions. Deoxyosones further evolve into many volatile and semi-volatile compounds and, in particular, 
A

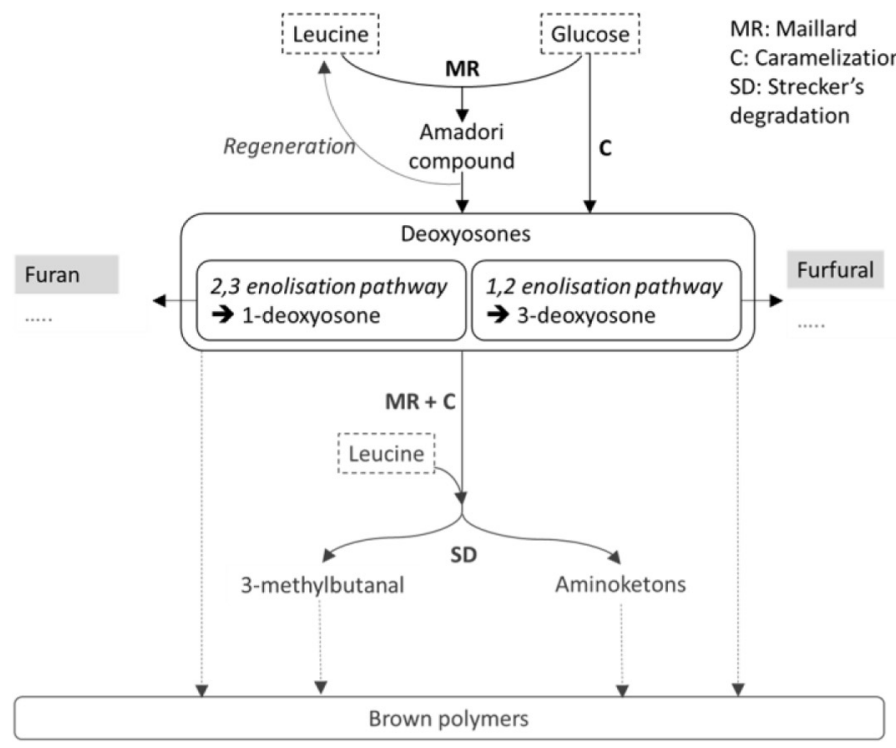

B

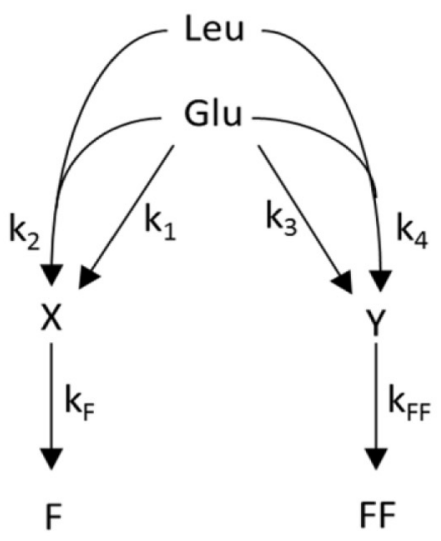

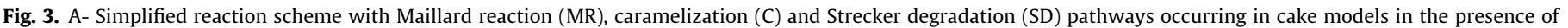

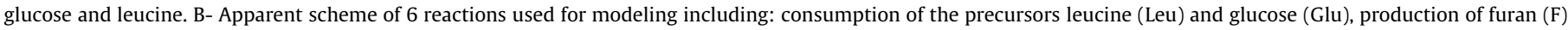
and furfural (FF) through two intermediates $(\mathrm{X}, \mathrm{Y})$; the associated kinetic rate constants $(\mathrm{k})$ are also shown.

furanic compounds. Finally, deoxyosones (formed from both $\mathrm{C}$ and MR routes) can also react with free leucine through the Strecker degradation pathway (SD) which leads to an aminoketone and to 3-methylbutanal, an aldehyde specific to the amino-acidic source (leucine). These species, together with other advanced products of the Maillard reaction, can further react and polymerize giving brown polymers. Based on analysis of the literature and taking into account the experimental conditions, this scheme assumes that furan is mainly formed by the 2,3-enolization pathway via the 1deoxyosone derivative (Crews \& Castle, 2007; Perez Locas \& Yaylayan, 2004; Stadler, 2012), while furfural is mainly formed by the 1,2-enolization pathway via the 3-deoxyosone (Kroh, 1994). The previous quantitative results showing that furfural is more prone to be formed than furan in the $G+L$ model (tab.2), suggesting that 1,2-enolisation could be thus favored over 2,3enolization.

Given the available experimental data, the reaction scheme was simplified into an apparent scheme (Fig. 3B), keeping only the initial substrates (glucose and leucine), two fictive direct precursors ( $\mathrm{X}$ and $\mathrm{Y}$ ) and both final products (furan and furfural). Kinetic modeling was then performed to identify the apparent kinetic rate constants for each of the 6 reactions.

Several hypotheses had to be made to limit the number of parameters to identify, according to the number of experimental data:

- The stoichiometry of the reactions was assumed to be mole to mole,

- The model was assumed isothermal,

- Furan and furfural were defined as terminal compounds,

- Initial concentrations of furan, furfural and of their direct precursors ( $\mathrm{X}$ and $\mathrm{Y}$ ) were considered null,

- The regeneration of leucine was not taken into account.

- The system was assumed closed

Following the reaction scheme, a system with 6 coupled differential equations was obtained based on the mass balance established for each compound involved in the reaction pathway.

$$
\left\{\begin{array}{l}
\frac{d G l c}{d t}=-k_{1} \cdot \text { Glc }-k_{3} \cdot \text { Glc }-k_{2} \cdot \text { Glc } \cdot \text { Leu }-k_{4} \cdot \text { Glc } \cdot \text { Leu } \\
\frac{d L e u}{d t}=-k_{2} \cdot \text { Glc } \cdot \text { Leu }-k_{4} \cdot \text { Glc } \cdot \text { Leu } \\
\frac{d X}{d t}=k_{1} \cdot \text { Glc }+k_{2} \cdot \text { Glc } \cdot \text { Leu }-k_{F} \cdot X \\
\frac{d Y}{d t}=k_{3} \cdot \text { Glc }+k_{4} \cdot \text { Glc } \cdot \text { Leu }-k_{F F} \cdot Y \\
\frac{d F}{d t}=k_{F} \cdot X \\
\frac{d F F}{d t}=k_{F F} \cdot Y
\end{array}\right.
$$

The resolution of this system was done using Matlab 2016b (MathWorks, Natick, MA) and the solver ode15s. The values of each parameter enabling us to obtain the least difference between modeled and experimental values were identified jointly using the Matlab function fminsearch. This difference was evaluated using a pondered sum of squares, in order to strictly give the same importance to furan and furfural in the identification process. The resulting calculated constants made it possible to estimate the degradation of the precursors and the formation of the products adequately. In fact, the substrates are degrading and the intermediary products ( $\mathrm{X}$ and $\mathrm{Y}$ ) are formed and degraded, with a particular bell-shaped curve obtained for $Y$ in the $G+L$ model (Fig. 4). Finally, the experimental concentrations of furan and furfural increasing with time are well described by the model.

The values of the kinetic rate constants identified: $k_{1}=$ $8.3 \cdot 10^{-7} \mathrm{~s}^{-1} ; \quad k_{2}=1.7 \cdot 10^{-3} \mathrm{~g} \mathrm{DM} \cdot \mathrm{mol}^{-1} \cdot \mathrm{s}^{-1} ; \quad k_{3}=1.2 \cdot 10^{-5} \mathrm{~s}^{-1} ; \quad k_{4}=$ $2.1 \cdot 10^{-1}$ g DM.mol ${ }^{-1} \cdot \mathrm{s}^{-1} ; k_{\mathrm{F}}=7.7 \cdot 10^{-6} \mathrm{~s}^{-1} ; k_{\mathrm{FF}}=3.4 \cdot 10^{-4} \mathrm{~s}^{-1}$; illustrate the trend shown in Fig. 4: furfural is formed faster than furan ( $k_{3}$ versus $k_{1} ; k_{2}$ versus $k_{4}$ and $k_{\mathrm{FF}}$ versus $k_{\mathrm{F}}$ ).

The reaction model here presented fits the experimental data for the reaction markers (Fig. 4A and B) despite its simplicity and proves that a multi-response modeling approach is feasible and valid. However, to obtain a more precise identification of the reaction rate constants, further experiments will be needed to broaden the database (precursors' concentration and different baking temperatures). Moreover, to improve the simplistic hypotheses made for the present study, a non-isothermal evolution of the model should be considered (results presented above showed that the temperature was not constant during baking). The regeneration 

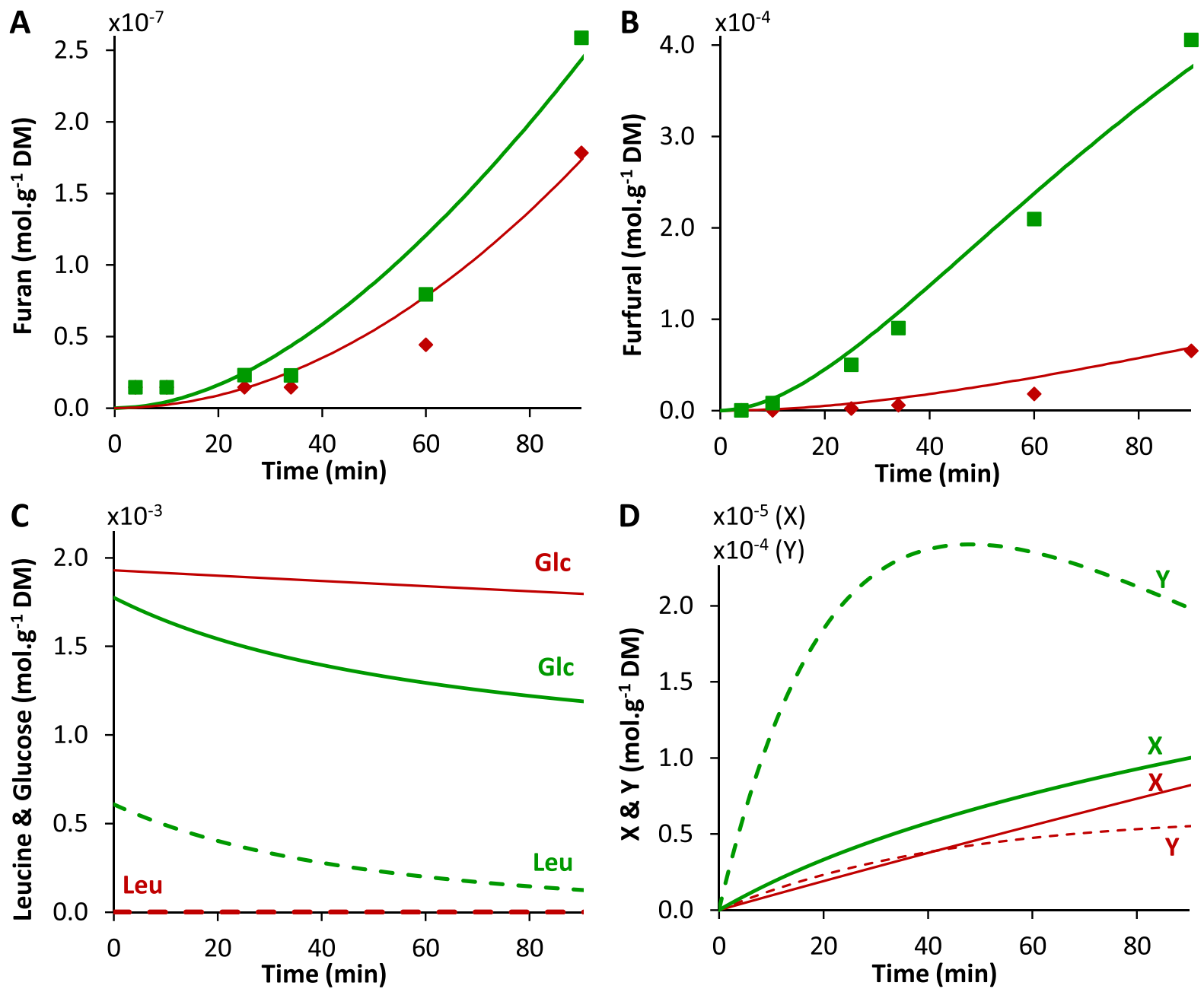

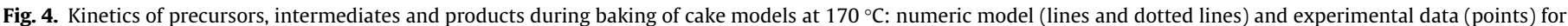

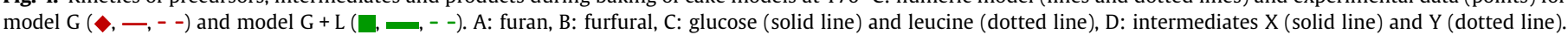

of leucine through Amadori degradation, (Yaylayan, HuyghuesDespointes, \& Feather, 1994) should also be incorporated into the model, as it would increase the concentration of available leucine with time. Finally, any consumption of furan and furfural through browning polymerization or evaporative loss during baking could also be taken into account at further steps.

\section{Conclusion}

This work provides a novel approach to understand, model and control the kinetics of thermal reactions in baked products under realistic baking conditions. This approach implements for the first time an inert cake model and proves its suitability as a tool to study Maillard and caramelization reactions towards processinduced-compounds generation, in particular furanic compounds.

The generation of furan and furfural as well as browning levels are found to be dramatically different in the two cake models ( $G$ \& $\mathrm{G}+\mathrm{L}$ ), despite applying the same baking conditions that resulted in similar thermal profile and dehydration process in both models. Furfural is clearly formed in higher amounts (ppm) than furan (ppb), regardless of the reaction system under study, either caramelization only (in $\mathrm{G}$ model) or jointly with Maillard reaction (in $\mathrm{G}+\mathrm{L}$ model). Also, furfural concentration is higher in model G + L than in model G, unlike furan content which remains almost the same in both reaction systems. Therefore, it can be inferred that furan formation under these process and reaction conditions does not seem to be as favored as furfural.
The kinetic model here developed adequately fits the experimental data and makes it possible to predict the consumption of precursors and the formation of two hypothetical intermediates. The modeling results also suggest that in the presence of glucose, the 1,2-enolisation intermediates, most likely 3-deoxyosone, are more rapidly formed and also more rapidly consumed than those of the 2,3-enolisation pathway, most likely 1-deoxyosone, leading to furan. Moreover, both enolisation pathways are enhanced in the presence of leucine.

Hence, this work opens wide perspectives for the understanding of chemical reactivity in baked goods; increasing the complexity of the cake model composition and broadening the range of baking conditions will make it possible to gain insight into more complex interactions and identify key factors. This strategy can be readily applied to other phenomena, including different reactivity systems (i.e. different pathways, precursors, reaction markers) and other process-induced compounds. In the long term, this work could be used in a formulation engineering approach, aiming at developing food safety strategies while preserving the sensory quality of baked cereal products.

\section{Funding}

This work was supported by IDEX Paris-Saclay, Region Ile-deFrance (DIM ASTREA), the Mexican National Council for Science and Technology (Consejo Nacional de Ciencia y Tecnología - CONACYT; grant: 314446) and the French Embassy in Mexico. 


\section{Conflict of interest}

The authors have declared no conflict of interest.

\section{Acknowledgment}

The authors wish to thank Dr. Mathieu Cladière for fruitful scientific discussion and Nicolas Descharles for valuable suggestions and technical support in HS trap analysis.

\section{Appendix A. Supplementary data}

Supplementary data associated with this article can be found, in the online version, at http://dx.doi.org/10.1016/j.foodchem.2017. 06.126 .

\section{References}

Aggarwal, P., \& Dollimore, D. (1998). A thermal analysis investigation of partially hydrolyzed starch. Thermochimica Acta, 319, 17-25.

Ait Ameur, L., Mathieu, O., Lalanne, V., Trystram, G., \& Birlouez-Aragon, I. (2007). Comparison of the effects of sucrose and hexose on furfural formation and browning in cookies baked at different temperatures. Food Chemistry, 101(4), 1407-1416.

Blank, I., Devaud, S., Matthey-Doret, W., \& Robert, F. (2003). Formation of odorants in Maillard model systems based on L-proline as affected by $\mathrm{pH}$. Journal of Agricultural and Food Chemistry, 51(12), 3643-3650.

Bousquières, J., Bonazzi, C., \& Michon, C. (2017). Food Hydrocolloids Rational design to develop a non-reactive model food imitative of a baked cereal product by replacing the functional properties of ingredients. Food Hydrocolloids, 63, 552-560.

Cepeda-Vázquez, M., Blumenthal, D., Camel, V., \& Rega, B. (2017). Multivariate optimization of headspace trap for furan and furfural simultaneous determination in sponge cake. Talanta, 164, 708-715.

Cho, H., \& Peterson, D. G. (2010). Chemistry of bread aroma: A review. Food Science and Biotechnology, 19(3), 575-582.

Crews, C., \& Castle, L. (2007). A review of the occurrence, formation and analysis of furan in heat-processed foods. Trends in Food Science \& Technology, 18(7), $365-372$.

Fehaili, S., Courel, M., Rega, B., \& Giampaoli, P. (2010). An instrumented oven for the monitoring of thermal reactions during the baking of sponge cake. Journal of Food Engineering, 101(3), 253-263.

Huault, L., Descharles, N., Rega, B., Bistac, S., \& Giampaoli, P. (2016). Furan quantification in bread crust : development of a simple and sensitive method using headspace-trap GC-MS. Food Additives \& Contaminants : Part A, 33(2), 236-243.

Hurtta, M., Pitkänen, I., \& Knuutinen, J. (2004). Melting behaviour of D-sucrose, Dglucose and D-fructose. Carbohydrate Research, 339, 2267-2273.

International Agency for Research Center on Cancer (1995). Dry cleaning, some chlorinated solvents and other industrial chemicals. IARC Monographs on the Evaluation of Carcinogenic Risks to Humans, 63, 393-407.

Kearsley, M. W., \& Dziedzic, S. Z. (1995). Handbook of starch hydrolysis products and their derivatives. US: Springer.

Kocadaglı, T., \& Gökmen, V. (2016). Multiresponse kinetic modelling of Maillard reaction and caramelization in a heated glucose/wheat flour system. Food Chemistry, 211, 892-902.

Kroh, L. W. (1994). Caramelisation in food and beverages. Food Chemistry, 51, 373-379.

Liu, H., Xie, F., Yu, L., Chen, L., \& Li, L. (2009). Thermal processing of starch-based polymers. Progress in Polymer Science, 1, 1348-1368.
Lutz, R., Aserin, A., \& Garti, N. (2005). Maillard Reaction between Leucine and Glucose in $\mathrm{O} / \mathrm{W}$ Microemulsion Media in Comparison to Aqueous Solution. Journal of Dispersion Science and Technology, 26(5), 535-547.

Mariotti-Celis, M. S., Zúñiga, R. N., Cortés, P., \& Pedreschi, F. (2017). A Kinetic Study of Furan Formation in Wheat Flour-Based Model Systems duringFrying. Journal of Food Science, 82, 232-239.

Nguyen, H. T., Fels-Klerx, H. J. (Ine) Van der, Peters, R. J. B., \& van Boekel, M. A. J. S (2016). Acrylamide and 5-hydroxymethylfurfural formation during baking of biscuits: Part I: Effects of sugar type. Food Chemistry, 192, 575-585.

Nie, S., Huang, J., Hu, J., Zhang, Y., Wang, S., Li, C., \& Ellipsis Xie, M. (2013). Effect of $\mathrm{pH}$, temperature and heating time on the formation of furan in sugar - glycine model systems. Food Science and Human Wellness, 2(2), 87-92.

Owczarek-Fendor, A., De Meulenaer, B., Scholl, G., Adams, A., Van Lancker, F., Eppe, G., \& De Kimpe, N. (2012). Furan formation in starch-based model systems containing carbohydrates in combination with proteins, ascorbic acid and lipids. Food Chemistry, 133(3), 816-821.

Pacyński, M., Wojtasiak, R. Z., \& Mildner-Szkudlarz, S. (2015). Improving the aroma of gluten-free bread. LWT - Food Science and Technology, 63, 706-713.

Palmers, S., Grauwet, T., Celus, M., Wibowo, S., Kebede, B. T., Hendrickx, M. E., \& Loey, A. Van. (2015). A kinetic study of furan formation during storage of shelfstable fruit juices. Journal of Food Engineering, 165, 74-81.

Perez Locas, C., \& Yaylayan, V. A. (2004). Origin and Mechanistic Pathways of Formation of the Parent Furan - A Food Toxicant. Journal of Agricultural and Food Chemistry, 52, 6830-6836.

Petisca, C., Henriques, A. R., Pérez-Palacios, T., Pinho, O., \& Ferreira, I. M. P. L. V. O. (2014). Assessment of hydroxymethylfurfural and furfural in commercial bakery products. Journal of Food Composition and Analysis, 33, 20-25.

Pico, J., Bernal, J., \& Gómez, M. (2015). Wheat bread aroma compounds in crumb and crust : A review. Food Research International, 75, 200-215.

Purlis, E. (2010). Browning development in bakery products - A review. Journal of Food Engineering, 99(3), 239-249.

Purlis, E., \& Salvadori, V. O. (2009). Modelling the browning of bread during baking. Food Research International, 42(7), 865-870.

Rannou, C., Laroque, D., Renault, E., Prost, C., \& Sérot, T. (2016). Mitigation strategies of acrylamide, furans, heterocyclic amines and browning during the Maillard reaction in foods. Food Research International, 90, 154-176.

Rega, B., Guerard, A., Delarue, J., Maire, M., \& Giampaoli, P. (2009). On-line dynamic HS-SPME for monitoring endogenous aroma compounds released during the baking of a model cake. Food Chemistry, 112(1), 9-17.

Samsudin, M. W., Rongtao, S., \& Said, I. M. (1996). Volatile Compounds Produced by the Reaction of Leucine and Valine with Glucose in Propylene Glycol. Journal of Agricultural and Food Chemistry, 44, 247-250.

Stadler, R. H. (2012). Heat-generated toxicants in foods: acrylamide, MCPD esters and furan. In D. Schrenk (Ed.), Chemical contaminants and residues in food (pp. 201-232). Woodhead Publishing Limited.

Vleeschouwer, K. De, Plancken, I. Van der, Loey, A. Van, \& Hendrickx, M. E. (2009). Modelling acrylamide changes in foods: from single- response empirical to multiresponse mechanistic approaches. Trends in Food Science E' Technology, 20 (3-4), 155-167.

Vranová, J., \& Ciesarová, Z. (2009). Furan in food - a review. Czech Journal of Food Sciences, 27(1), 1-10.

Wegener, J.-W., \& López-Sánchez, P. (2010). Furan levels in fruit and vegetables juices, nutrition drinks and bakery products. Analytica Chimica Acta, 672, 55-60.

Whitfield, F. B. (1992). Volatiles from Interactions of Maillard Reactions and Lipids. Critical Reviews in Food Science and Nutrition, 31(1), 1-58.

Yaylayan, V. A., Huyghues-Despointes, A., \& Feather, M. S. (1994). Chemistry of Amadori rearrangement products: Analysis, synthesis, kinetics, reactions, and spectroscopic properties. Critical Reviews in Food Science and Nutrition, 34(4), 321-369.

Zhang, Y.-Y., Song, Y., Hu, X.-S., Liao, X.-J., Ni, Y.-Y., \& Li, Q.-H. (2012). Effects of sugars in batter formula and baking conditions on 5-hydroxymethylfurfural and furfural formation in sponge cake models. Food Research International, 49, 439-445.

Zoller, O., Sager, F., \& Reinhard, H. (2007). Furan in food : Headspace method and product survey. Food Additives and Contaminants, 24, 91-107. 